\title{
HEMBYGD - A CONCEPT AND ITS AMBIGUITIES
}

\section{Maria Björkroth}

One popular movement, the 'hembygd'-movement, has been a particularly dynamic force in shaping Swedish attitudes towards museums and cultural heritage. The movement was born in the first decades of the 20th century, it attracted young people and it soon had spread throughout the country. It has undoubtedly had a profound impact, but it has been only superficially studied. The aim of this paper is to contribute to an understanding of how the past, in terms of cultural heritage, tradition and native district, has been used in the creation of our modern Swedish society. The past is explicitly used for the construction of the future and the process could be described as «Cultural and Environmental Recycling».

The Swedish word hembygd is a central term embodying simultaneously both the name of the movement and its core concept. It is present in the name of many local museums and it is commonly used to signify one's native place. Literally it means «one's native (home) district»; its German equivalent is Heimat. But both translations are problematic because of their connotations. A short explanation will serve to clarify the meaning of the Swedish concept hembygd.

The word is basically constructed from two single words, hem and bygd. Hem is home. Bygd denotes a geographic district, but it also has a lot of specific connotations. It is mostly a small district that is first and foremost a cultural unit, but secondly it is a unit bound together both socially and economically. It is not necessarily however an area that coincides with a government administration district or a Church parish. Bygd is a topographical or rather a chorological term which divides or unites districts across administrative borders. Bygd has also been the major structuring principle for Swedish folk life studies, the use of the term has been especially prominent from the 1930s and onwards.

\section{THE PHYSICAL SETTING AND THE MENTAL LANDSCAPE}

When you put the words hem and bygd together you get hembygd. Today the chorological meaning is dominant - both the physical setting and the mental landscape are included, but the second element is 
34 the most important. The two elements come together in the cultural heritage. The name of the site, the village or the neighbourhood that has given the hembygd its name is sacred on a symbolic level. The symbolic level of the concept is important, because without it, it is impossible to understand that the term can be interesting and analytically elaborated.

The analytic framework for a study of the role of the cultural heritage can in short be described in the following way: On the one hand the past is treated as something that is supposed not to be an obstacle to development but has to be defined and isolated. The past is transferred to archives and to museums as a testimony to society of what modernity has left behind. On the other hand the past is valued, its best and strongest parts are supposed to make modernity itself better for society.

Two preservation strategies can be derived from those attitudes towards the past: the first is simply interested in pure, preferably old, artefacts and offers collections of nice - not too big - artefacts (narrations, material objects, traditions, music, national parks etc.). The other strategy focuses not on the artefact itself, but on its use and the message it communicates. In this context the specific strategy for preservation propagated by the hembygd movement is located - hembygdsvard, i.e. care of the hembygd. It is undoubtedly here that the ideas of the movement are most clearly developed and expressed.

Hembygd as a concept was first introduced in literature about 1870-1880, but not until a couple of decades later did it become the centre of an alternative idea about the shaping of our modern society.
At the beginning of this century optimism reigned concerning the building of modern society. The hembygd-movement shared this optimism. A frequent metaphor was that the future should be built on the foundations of the past. The adherents of the movement were convinced that the best of the old and the best of the new could and should be united. Old farms and new technology were met with the same euphoric appreciation and enthusiasm. A well-run farm, church-like factories and new transportation technology - steamboats and trains - were all promises of a better future. The smoke from the huge chimney-stacks and the waste water of industries and cities were not yet seen as problems. It was known that factories could poison their environment, but it was regarded only as the result of bad planning, wrong localization or mismanagement, all man-made problems that could be solved.

I will quote one of the pioneers of the hembygd-movement, Karl-Erik Forsslund, who wrote in 1914:

The question is not industry or handicraft, mass production or home-production. Like everything else there are two sides to this issue. Certainly we must have modern industry. The car is a wonderful vehicle. The aircraft is one of mankind's most beautiful creations and they cannot be homemade. The electric light and electric power are victories and conquests of the most honourable kind. A big powerstation, a big factory can be fairy castles. But we also have to demand that they are planned and built in a proper way.

There are several similarities between what happened in Sweden and what was going on in other European countries. Inter- 

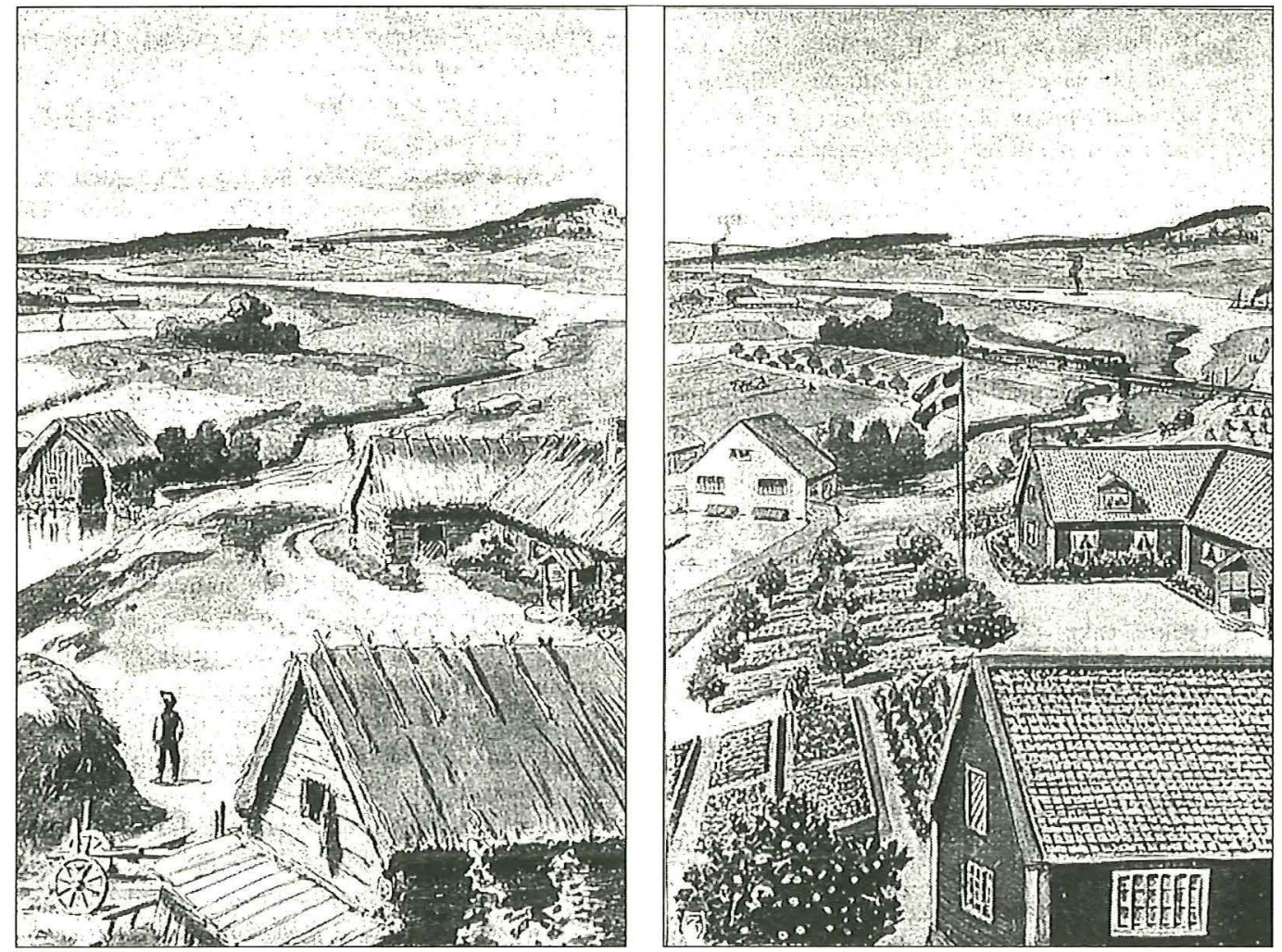

"The home of Jerker as it was and as it has become». An illustration in a fairytale from the book Swedish Youth (1908). Jerker is shown by a fortune-teller with magic spectacles how his native place will look in the future if he rebuilds the farm according to her advice.

national conferences on the theme were held in Paris in 1909 and in Stuttgart in 1912. An organization similar to that in Sweden was founded in Denmark in 1907. The hembygd-work in Sweden was strongly influenced from Norway and Finland and by the movements for Heimatschutz and Heimatpflege in Germany. In Karl-Erik Forsslund's book from 1914, there are translations of some German texts in the field.

\section{AN EXPERT ORGANIZATION IS BORN}

I have studied a Swedish organization founded in 1916, Samfundet for Hembygdsvård (SfH) which literally means 'The Association for the care of the hembygd'. But the English version used by the organization was 'The Association for the
Preservation of Local Nature and Culture'. Its foundation was foreshadowed by Svenska Teknologforeningen ('The Swedish Technologist Association') at Tekniska Högskolan, KTH ('The Royal Institute of Technology'). One of the founders was the famous architect Lars Israel Wahlman, Professor of Building Science at KTH.

The organization was thus created to offer an economic basis for consultancy activities. The founders wanted to link the best of Swedish history and traditions with modern building and town planning in the ongoing work of developing a modern industrialized nation. No issue was too big or too small. In the following decades this ideology combined such things as advice about new chimneys in private homes, infrastructural issues, buildings, towns and roads. 
MARIA BJÖRKROTH

The consultancy office of $S f H$ started in 1916 with one architect, John Akerlund, employed fulltime. Given the founding background it is easy to understand that the main issues for the new organization were building and town planning and $S f H$ can initially be regarded as part of a contemporary townplanning movement. The first consultancies in 1916-17 were connected with town plans. The Act for Regulation of Town Planning was passed in 1908 , but there were only a few architects in Sweden to implement it. Some of the issues SfH handled, led to the establishment of positions for town architects, e.g. in the towns of Södertälje and Gävle. Town planning in those days was naturally applied to very limited areas. But it was an ambition of the $S f H$ also to contribute to sensible building outside town-planned areas. On principle they supported private building projects, both small farms in the districts and owner-occupied one- or two-family houses in the close surroundings of cities. If their prototype drawings were used, the families were granted lowrate government loans to cover the building costs.

One of the main concepts governing the prototype drawings was the analysis of tradition, which meant selecting those parts of the local building traditions considered most valuable and using them to create new forms. The analysis was presented in the form of prototype drawings which were supposed to re-insert the corrective strength of tradition and at the same time advise about acceptable modern building techniques.

Another way of improving the available building skill was to train builders.

Building courses were provided both together with local associations all over the country and also arranged independently. A special school for professional contractors gave annual courses from 1915 to 1946 .

\section{LOCAL ASSOCIATIONS AND MUSEUMS}

However, SfH simultaneously organized the local associations for the care of hembygd and local traditions that had sprung up all over the country and were constantly becoming more numerous. In 1919 a new subject, hembygdskunskap, ('local geography and history') was introduced in the curriculum of the compulsory school. Board members and staff of SfH were engaged as instructors to introduce the subject in teachers' training. This gives an idea about the ideological power of the hembygd movement at that time. Information was also given in the school books about how local hembygd associations could be organized. In the history of the movement school teachers have played an indisputable part as founders and leaders of the local associations. Those are mainly known today for running local open air museums and small museums.

A few local open air museums were opened during the first decade of the 20th century using the concept of the famous Skansen in Stockholm. At the beginning of 1910 there was a break-through for the small open air museum, the Gammelgard. We probably regard the Gammelgard as a museum among other museums today, but the term was originally coined in opposition to the conventional museum. The Gammelgard - the word actually 
A small farm-house from Mora in the province of Dalecarlia, exhibited at Skansen, Stockholm in 1891.
A prototype drawing (1928) by the district architect Magnus Dablander, chairman of the building department of the Dalecarlian hembygd association. The porch and the chimney pot are meant to be suggestive of the local building tradition, the so-called Mora type.
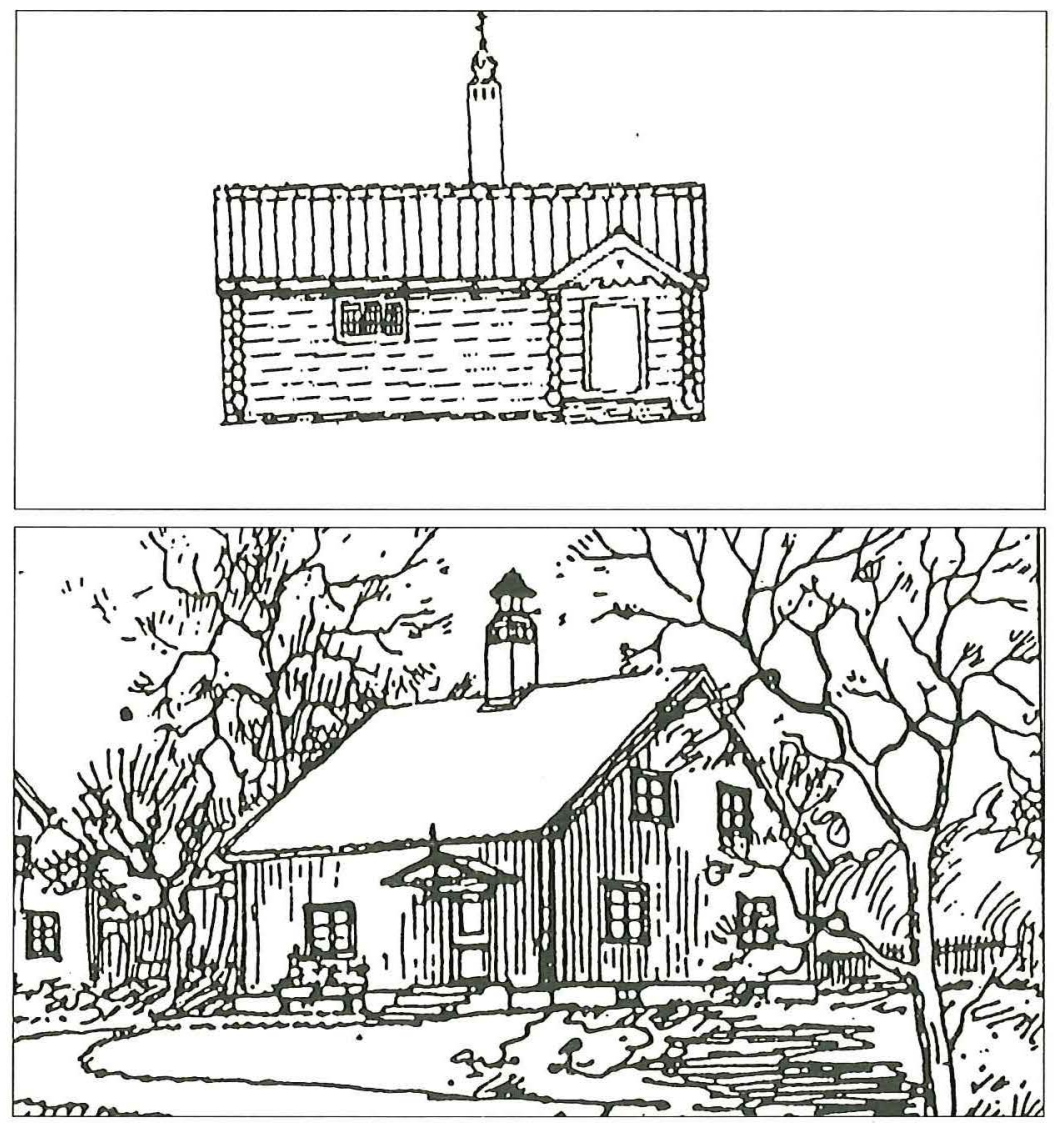

means old farmstead - was supposed to become the heart of the municipality, a meeting-place for the inhabitants, where its historic treasures could be contemplated - the best of local material culture and traditional buildings serving as inspiration for future development. They were part of the practical work of protection and preservation of the local hembygd. However the fashioning of new buildings, parks and town plans made up the other part of the programme. The chairman of $S f H$, Karl Starbäck, wrote in 1920 about the obligation to participate in the building of society:
The other side of the work of $S f H$ is directed at influencing ongoing construction projects and at remodelling. This represents a field of activity of considerable size: communications and sites for industrial mass production, the building of new villages and single farms, the planning of towns and their parks, squares and streets.

In the 1920s several municipalities organised special boards for hembygd work in their areas. They used the SfH consultancy for issues concerning building and town planning. 
TRADITION AND MODERNISM IN ARCHITECTURE

In 1924 SfH arranged an exhibition of modern industrial buildings, Beautiful factories. John Åkerlund, head of the exhibition wrote:

How these big constructions are handled, might be seen as a minor question for the protection of environment, although they always encroach on nature. But everywhere where we have to accept such intrusions in the name of the inhabitants of our country, e.g. new villages, new industries and - in connec- tion with this - new or expanded communication systems, we do not have to surrender and believe that there is nothing more to be done. When this happens, we must take care that the changes do not violate nature and that they are made as beautifully and with as much consideration as possible for the area which was sacrificed.

In the beginning only associations, companies, municipalities and private sponsors could become members of SfH. In 1923 it was decided that also private persons could be admitted.

A new Building Act was passed in 1932

No. 15, a one-family home, from a collection of 23 prototype drawings published in 1935 by the SfH architect group.

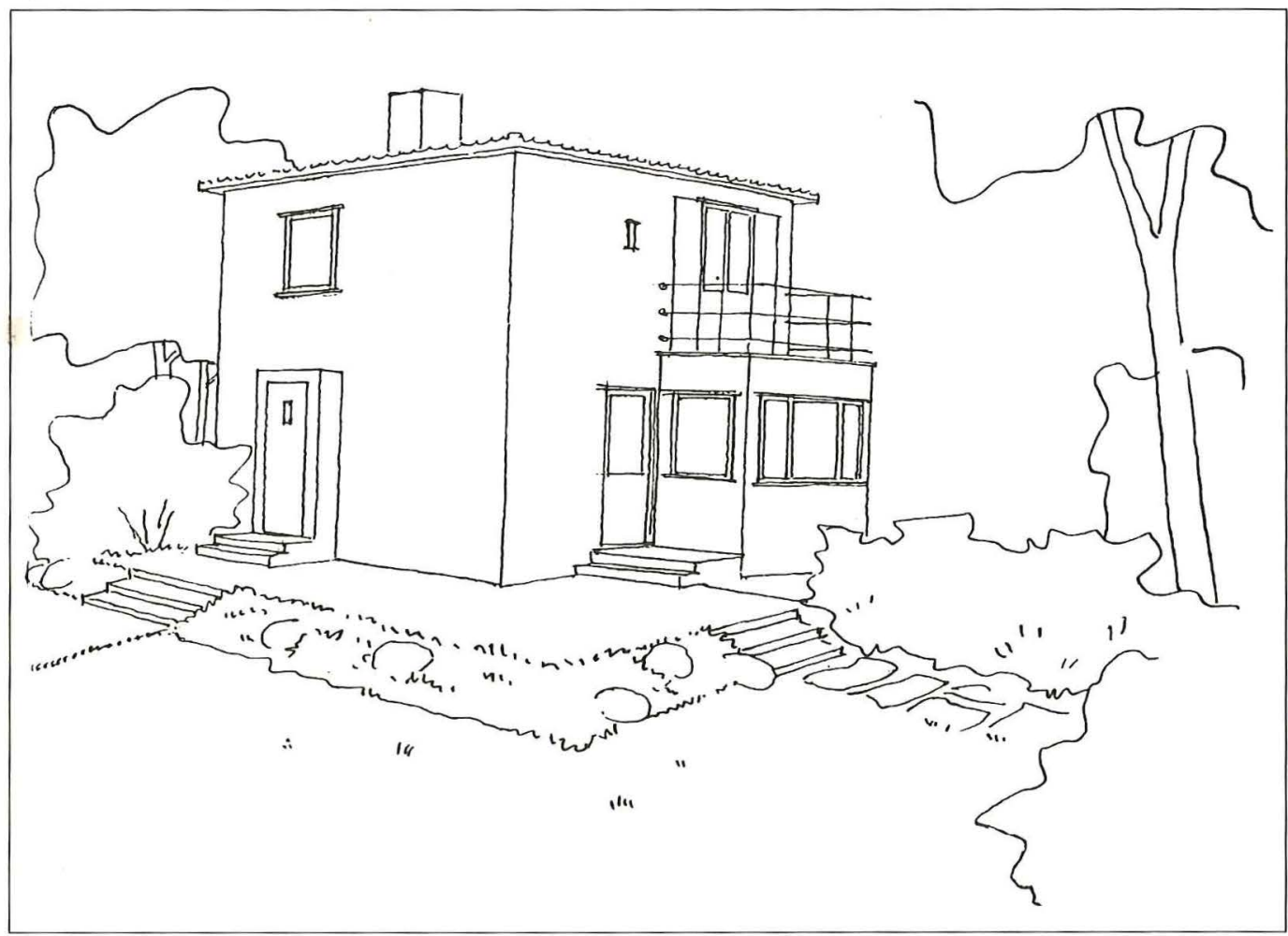


according to which all municipalities were forced to elect a building committee and the towns had to employ their own architects. The consequence for $S f H$ was that the demand for building consultancy decreased and in the following years the membership dropped with $10-15 \%$ a year. The crisis culminated in 1935.

Then $S f H$ was reorganized. In the late 1930 s it tried to find new tasks in the building field. A separate corporation for information about building methods and materials was founded in 1933. It still exists today.

Not just legislation but time also influenced change in the work. The Stockholm Exhibition of 1930 is seen as the breakthrough of functionalism in Sweden. Architects were divided in favour of or against the new style and ideals. The hembygd architecture favoured by $\mathrm{SfH}$, which tried to combine a modern strictly functionalist use of old building elements with traditional form was criticized from both sides. For functionalist architects it was too traditional, for the traditionalists it was too functionalist.

\section{NATURE CONSERVATION}

SfH had thus performed pioneer work in the fields of building and town planning, before the introduction of functionalism and modern building legislation. Subsequently another so far unregulated field nature conservation - became the most important field of activity for $S f H$.

The preservation ideology, represented by $S f H$, was appropriate for nature conservation, especially in connection with largescale construction projects resulting in farreaching environmental changes. Instead of serving as experts for municipalities 39 and private persons regarding building issues, the $S f H$ experts now came to serve the government in investigations into road systems and water-power exploitation. The new orientation became evident towards the end of the 1930's. A department for nature conservation and preservation was organized within $S f H$. The ideology of the organization in its practical work of hembygd preservation was applied to the new tasks. It was formulated as formative and preservational nature conservation.

In this field $S f H$ received official recognition. At the end of 1939 the Ministry of Communications appropriated public funds for a government road consultant within $S f H$ for the preservation of nature in connection with both newly built highways and the rebuilding of the old major road system.

The first period was dominated by investigations concerning the Swedish highway system. The road consultancy introduced modern road planning techniques in Sweden after both planning and new technology had been studied in Germany and the United States. In 1960 for example a project was carried out resulting in what has been called the most beautiful highway in Sweden. The localization of the new international airport at Stockholm, Arlanda, was also investigated by $S f H$ and is a result of their work.

When a Nature Protection Act was passed in 1952 , the position of $S f H$ was strengthened. According to the directions for the application of the Act, the department was given expert status and was seen as the body to which the proposed measures from the Government concerning issues of 
40 nature conservation should be referred for consideration. Following a suggestion from the Minister for Agriculture a special office for issues concerning hydroelectric power was organized. During the 1950s the majority of investigations commissioned by the government were concerned with the expansion of hydroelectric power construction. Every river and lake that was harnessed before the 1960 s was investigated by $S f H$. Because of the difficulties of environmental protection experienced in connection with the hydroelectric power development, nuclear power was welcomed as an environment friendly alternative and the localization of Swedish nuclear power plants was also investigated by $S f H$.

When the idea of connecting preservation with construction was put into practise, the reshaping of the natural setting was considered the main point - at least as important as the preservation aspect. In its program for formative conservation $S f H$ persisted in the ideology previously expressed as an 'analysis of tradition'.

A new Nature Conservation Act was passed in 1964. This ended the consultancy on roads and landscape issues at $S f H$, and the building consultancy closed down a couple of years later. As a result of the Act the Government in 1967 set up Naturvardsverket ('The National Environment Protection Board').

\section{RETURN TO THE HEMBYGD}

SfH represented a way of looking at the past and the future together which has had a strong influence on Swedish society. The working method they represented was applied to widely different tasks such as the building of highways, hydroelectric and nuclear power plants, and Arlanda airport."

What remains in the movement today are the 'purely' hembygd matters carried on in the local associations. They are commonly regarded as just nostalgic groupings, but originally, as I have shown, their interest in the past was only part of an ideological commitment within the modernization project.

SfH has accordingly been re-named Sveriges Hembygdsforbund ('The Union of Associations for the Care of 'hembygden') and assists the local associations in their various fields of action.

The idea of hembygd and the prevailing interest in local history, beliefs and tradition shows us that the past lives on in our modernized society and can be used as a force in economics, in politics and in ecology. There is still a lot of research to be done concerning which parts of the hembygd-ideology, born at the turn of the century, are still active within our society and its citizens. On the whole the word hembygd has lost most of its ideological charge and its nostalgic connotation now predominates.

Maria Björkroth is an ethnologist working as assistant director at the Office of Cultural heritage at the Regional Administration Dalecarlia, Falun. Adr: Länsstyrelsen i Kopparbergs län, S-79184 Falun. 